\title{
Taxonomic evaluation of the Streptomyces griseus clade using multilocus sequence analysis and DNA-DNA hybridization, with proposal to combine 29 species and three subspecies as 11 genomic species
}

\author{
Xiaoying Rong and Ying Huang
}

State Key Laboratory of Microbial Resources, Institute of Microbiology, Chinese Academy of Sciences, Beijing 100101, PR China

\begin{abstract}
Streptomyces griseus and related species form the biggest but least well-defined clade in the whole Streptomyces 16S rRNA gene tree. Multilocus sequence analysis (MLSA) has shown promising potential for refining Streptomyces systematics. In this investigation, strains of 18 additional S. griseus clade species were analysed and data from a previous pilot study were integrated in a larger MLSA phylogeny. The results demonstrated that MLSA of five housekeeping genes $(\operatorname{atp} D, g y r B, \operatorname{rec} A, r p o B$ and $\operatorname{trp} B)$ is better than the previous six-gene scheme, as it provides equally good resolution and stability and is more cost-effective; MLSA using three or four of the genes also shows good resolution and robustness for differentiating most of the strains and is therefore of value for everyday use. MLSA is more suitable for discriminating strains that show $>99 \% 16$ S rRNA gene sequence similarity. DNA-DNA hybridization (DDH) between strains with representative MLSA distances revealed a strong correlation between the data of MLSA and $\mathrm{DDH}$. The $70 \% \mathrm{DDH}$ value for current species definition corresponds to a five-gene MLSA distance of 0.007 , which could be considered as the species cut-off for the $S$. griseus clade. It is concluded that the MLSA procedure can be a practical, reliable and robust alternative to DDH for the identification and classification of streptomycetes at the species and intraspecies levels.

Based on the data from MLSA and DDH, as well as cultural and morphological characteristics, 18 species and three subspecies of the $S$. griseus clade are considered to be later heterotypic synonyms of 11 genomic species: Streptomyces griseinus and Streptomyces mediolani as synonyms of Streptomyces albovinaceus; Streptomyces praecox as a synonym of Streptomyces anulatus; Streptomyces olivoviridis as a synonym of Streptomyces atroolivaceus; Streptomyces griseobrunneus as a synonym of Streptomyces bacillaris; Streptomyces cavourensis subsp. washingtonensis as a synonym of Streptomyces cyaneofuscatus; Streptomyces acrimycini, Streptomyces baarnensis, Streptomyces caviscabies and Streptomyces flavofuscus as synonyms of Streptomyces fimicarius; Streptomyces flavogriseus as a synonym of Streptomyces flavovirens; Streptomyces erumpens, 'Streptomyces ornatus' and Streptomyces setonii as synonyms of Streptomyces griseus; Streptomyces graminofaciens as a synonym of Streptomyces halstedii; Streptomyces alboviridis, Streptomyces griseus subsp. alpha, Streptomyces griseus subsp. cretosus and Streptomyces Iuridiscabiei as synonyms of Streptomyces microflavus; and Streptomyces californicus and Streptomyces floridae as synonyms of Streptomyces puniceus.
\end{abstract}

Abbreviations: DDH, DNA-DNA hybridization; ML, maximum-likelihood; MLSA, multilocus sequence analysis; MP, maximum-parsimony; $\mathrm{NJ}$, neighbour-joining.

The GenBank/EMBL/DDBJ accession numbers for the sequences obtained in this study are detailed in Table 1.

Details of the loci studied, three- and four-gene concatenated NJ trees and correlation of MLSA distances and DDH results for individual genes are available as supplementary material with the online version of this paper.

\section{INTRODUCTION}

The genus Streptomyces remains a focus of systematics research, not only because streptomycetes are still a promising source of commercially significant compounds, but also because of taxonomic difficulties within the genus caused by the large number of isolates and insufficient species definition. The classification of streptomycetes is strongly influenced by polyphasic taxonomy, taking into 
account genetic characteristics as well as phenotypic characteristics (Kämpfer, 2006). Nevertheless, closely related Streptomyces species within species groups are incompletely circumscribed (Kämpfer, 2006; Lanoot et al., 2005a).

It is arguable whether the 16S rRNA gene should be considered to be a 'gold standard' for bacterial phylogeny (Vandamme et al., 1996), as this gene has multiple copies in a single genome of many bacteria (Acinas et al., 2004) and is apparently insufficient to distinguish between closely related species, notably species within Streptomyces clades (Guo et al., 2008; Liu et al., 2005). Since the ad hoc committee proposed the combined use of several housekeeping genes for re-evaluation of the species definition in bacteriology (Stackebrandt et al., 2002), multilocus sequence analysis (MLSA) has shed new light on bacterial systematics and phylogeny. This approach has been widely applied to unravel taxonomic relationships in a number of genera, including Streptomyces (Guo et al., 2008; Martens et al., 2007, 2008; Mignard \& Flandrois, 2008; Naser et al., 2006; Young et al., 2008).

Streptomyces griseus and related species form the biggest clade in the Streptomyces 16S rRNA gene tree (our unpublished data), with the majority of species sharing identical or highly similar $16 \mathrm{~S}$ rRNA gene sequences and similar phenotypes. As prolific producers of bioactive secondary metabolites, species of the S. griseus clade have been subjected to several molecular and polyphasic taxonomic studies (Guo et al., 2008; Lanoot et al., 2005b;
Liu et al., 2005), the results of which show that this clade as currently constituted is overspeciated. It is always a big challenge to identify unknown Streptomyces strains that fall into this clade, because the currently required method, DNA-DNA hybridization (DDH), is labour-intensive, time-consuming and provides non-cumulative data (Gevers et al., 2005, 2006; Rosselló-Mora, 2006).

In an effort to clarify the taxonomic structure of the $S$. griseus clade and to search for alternative methods of species delineation within Streptomyces, we developed a pilot streptomycete MLSA scheme using the $S$. griseus clade as a model in our previous study (Guo et al., 2008), and showed its potential for refining the phylogeny of Streptomyces. In the present investigation, strains of 18 additional species and subspecies of this clade and related species were examined and results from the previous study were integrated in a larger MLSA phylogeny. A better concatenation of assorted sequences was determined, and MLSA data were compared with DDH values to evaluate the potential of MLSA as a valuable alternative to DDH for the identification and classification of streptomycetes to the species level.

\section{METHODS}

Strains and culture conditions. Eighteen strains in addition to those included in the previous study (Guo et al., 2008), which were found to have high sequence similarities with the $S$. griseus clade, were included in this study. The 18 additional strains are shown in Table 1. All of the strains were cultivated on yeast extract/malt extract agar (ISP medium 2; Shirling \& Gottlieb, 1966) plates at $28^{\circ} \mathrm{C}$.

Table 1. Additional Streptomyces strains used in this study and GenBank accession numbers

$16 \mathrm{~S}$ rRNA gene sequences were obtained from other deposits of the strains and were obtained from GenBank. Other sequences were obtained in this study.

\begin{tabular}{|c|c|c|c|c|c|c|}
\hline Strain & 16S rRNA gene & $a t p D$ & gyrB & recA & rpoB & $\operatorname{trpB}$ \\
\hline S. atratus CGMCC $4.1632^{\mathrm{T}}$ & DQ026638 & EF661707 & EF661728 & EF661749 & EF661770 & EF661791 \\
\hline S. baarnensis CGMCC $4.1607^{\mathrm{T}}$ & $\mathrm{AB} 184615$ & EF661708 & EF661729 & EF661750 & EF661771 & EF661792 \\
\hline $\begin{array}{l}\text { S. cavourensis subsp. washingtonensis CGMCC } \\
4.1635^{\mathrm{T}}\end{array}$ & DQ026671 & EF661710 & EF661731 & EF661752 & EF661773 & EF661794 \\
\hline S. cinereorectus CGMCC $4.1622^{\mathrm{T}}$ & AY999764 & EF661711 & EF661732 & EF661753 & EF661774 & EF661795 \\
\hline S. flavofuscus CGMCC $4.1938^{\mathrm{T}}$ & EF178690 & EF661713 & EF661734 & EF661755 & EF661776 & EF661797 \\
\hline S. flavovirens CGMCC $4.575^{\mathrm{T}}$ & $\mathrm{AB} 184834$ & EF661714 & EF661735 & EF661756 & EF661777 & EF661798 \\
\hline S. gelaticus CGMCC $4.1444^{\mathrm{T}}$ & DQ026636 & EF661715 & EF661736 & EF661757 & EF661778 & EF661799 \\
\hline S. globosus CGMCC 4.320 & AJ781330* & EF661717 & EF661738 & EF661759 & EF661780 & EF661801 \\
\hline S. griseorubiginosus CGMCC $4.1766^{\mathrm{T}}$ & FJ405905 & EF661718 & EF661739 & EF661760 & EF661781 & EF661802 \\
\hline S. halstedii CGMCC $4.1358^{\mathrm{T}}$ & FJ405902 & EF661719 & EF661740 & EF661761 & EF661782 & EF661803 \\
\hline S. rubiginosohelvolus CGMCC 4.127 & AY999864* & EF661726 & EF661747 & EF661768 & EF661789 & EF661810 \\
\hline S. sanglieri CGMCC $4.1146^{\mathrm{T}}$ & AB249945 & EF661727 & EF661748 & EF661769 & EF661790 & EF661811 \\
\hline
\end{tabular}

${ }^{\star}$ Sequence obtained from the type strain. 
DNA extraction, amplification and sequencing. Genomic DNAs from the strains were isolated and purified as described by Chun \& Goodfellow (1995). PCR amplification and sequencing of four housekeeping genes, atpD, $\operatorname{rec} A, \operatorname{rpoB}$ and $\operatorname{trp} B$, were performed using primers and amplification conditions described by Guo et al. (2008). Amplification and sequencing of $\mathrm{gyrB}$ were conducted as described by Rong et al. (2009).

Phylogenetic analysis. Gene sequences of the 18 additional strains combined with our previous data for 53 strains were subjected to phylogenetic analysis. Phylogenies were constructed of the $16 \mathrm{~S}$ rRNA gene, each of the five protein-encoding genes and various concatenations of the genes. Sequences of the 16S rRNA gene and each locus were aligned using MEGA 4.0 software (Tamura et al., 2007) and trimmed manually at the same position before being used for further analysis and submitted to the PubMLST database (http:// pubmlst.org/streptomyces). Sequences of protein-encoding loci were concatenated by joining head-to-tail in-frame. Phylogenetic trees were constructed using three tree-making algorithms, neighbourjoining (NJ), maximum-parsimony (MP) and maximum-likelihood (ML). The NJ and MP methods were from the MEGA 4.0 package with the option of complete deletion of gaps; the topologies of the resultant trees were evaluated in bootstrap analysis (Felsenstein, 1985) of 1000 resamplings. The K2P model (Kimura, 1980) was chosen as a substitution model for $\mathrm{NJ}$ tree construction. ML analysis was performed with parameters selected by the Akaike information criterion (Akaike, 1974) in ModelTest 3.7 (Posada \& Crandall, 1998). The best-fit model GTR $+\mathrm{I}+\mathrm{G}$ was chosen for ML tree construction, conducted by PAUP ${ }^{*} 4.0 \mathrm{~b} 10$ (Swofford, 2002) using heuristic tree search with TBR branch swapping and 10 random addition replicates. The ML tree was also inferred by using the PHYLIP package version 3.68 (DNAML program) (Felsenstein, 2008) with 100 replicates. The resulting trees were combined to yield a consensus tree (CONSENSE program in PHYLIP).

DDH. Levels of DNA-DNA relatedness between strains of representative MLSA evolutionary distances (see Table 2) were determined by using the fluorometric microwell method (Ezaki et al., 1989) and the modifications described by $\mathrm{He}$ et al. (2005). Briefly, biotinylated DNA fragmented by ultrasonication to $400-700$ bp was denatured and hybridized with unlabelled ssDNA, which was absorbed non-covalently to the microplate wells. Hybridizations were performed in a hybridization mixture $(2 \times$ SSC, $5 \times$ Denhardt's solution, $50 \%$ formamide, $100 \mu \mathrm{g}$ denatured salmon sperm DNA $\mathrm{ml}^{-1}$ and $1 \mu \mathrm{g}$ biotinylated probe DNA ml$l^{-1}$ ) overnight at $53{ }^{\circ} \mathrm{C}$. A Fluostar Optima microplate reader (BMG LABTECH) was used for fluorescence measurements (excitation at $360 \mathrm{~nm}$ and emission at $460 \mathrm{~nm}$ ). Reciprocal hybridization (i.e. $\mathrm{A} \times \mathrm{B}$ and $\mathrm{B} \times \mathrm{A}$ ) was performed in triplicate for each pair of strains. The hybridization value was expressed as a mean of the corresponding reciprocal values. More than half of the strain pairs were examined in different batches of hybridization experiments.

Correlation between sequence analysis and DDH. Values of MLSA evolutionary distance, single-gene sequence evolutionary distance and corresponding DDH were compiled, containing all mean DDH values from different experimental batches, and were processed in Microsoft Excel. Correlation coefficients $\left(r^{2}\right)$ between the distance and DDH values were calculated by linear regression analysis.

\section{RESULTS AND DISCUSSION}

\section{Individual gene analyses}

Almost-complete 16S rRNA gene sequences (1377 nt) of the 71 tested strains were used for phylogenetic analysis. The results showed that sequence identities between strains ranged from 94.7 to $100 \%$; the proportion of variable sites was $9.3 \%$ (128 sites), with an overall mean distance of 0.016 . The strains can be grouped into 12 major clusters (labelled I-XII) in the 16S rRNA gene NJ tree (Fig. 1a). Within each of clusters I, II, IV and V, shaded in colour in Fig. 1, strains shared identical 16S rRNA gene sequences. Clusters VI, VIII, X, XI and XII were relatively heterogeneous, within each of which some strains also shared identical sequences. Strains of clusters III, VII and IX were generally well separated, with sequence distances ranging

Table 2. DDH and MLSA evolutionary distance values among strains of the $S$. griseus clade and related species

\begin{tabular}{|c|c|c|c|c|}
\hline Species 1 & Species 2 & DDH value (\%) & $\begin{array}{l}\text { MLSA evolutionary } \\
\text { distance }\end{array}$ & $\begin{array}{l}\text { MLSA phylogenetic } \\
\text { cluster }\end{array}$ \\
\hline S. californicus & S. puniceus & 87.7 & 0.001 & VI \\
\hline S. californicus & S. floridae & 89.6 & 0.002 & VI \\
\hline S. alboviridis & S. griseus subsp. alpha & 83.7 & 0.002 & IV \\
\hline S. floridae & S. puniceus & 84.4 & 0.002 & VI \\
\hline S. flavogriseus & S. flavovirens & $88.3 / 86.6 / 87.7$ & 0.004 & VIII \\
\hline S. acrimycini & S. baarnensis & $86.5 / 80.5 / 85.9$ & 0.005 & $\mathrm{Ia}$ \\
\hline S. graminofaciens & S. halstedii & 77.3 & 0.005 & $\mathrm{X}$ \\
\hline S. acrimycini & S. flavofuscus & $84.1 / 83.5 / 81.9$ & 0.006 & Ia \\
\hline S. griseus subsp. alpha & S. luridiscabiei & 79.3 & 0.006 & $\mathrm{~V}$ \\
\hline $\begin{array}{l}\text { S. cavourensis subsp. } \\
\text { washingtonensis }\end{array}$ & S. cyaneofuscatus & 75.9 & 0.007 & III \\
\hline S. alboviridis & S. luridiscabiei & $76.6 / 78.6$ & 0.007 & IV \\
\hline S. griseus subsp. griseus & 'S. ornatus' & $80.5 / 78.9$ & 0.007 & II \\
\hline S. argenteolus & S. galilaeus & $42.1 / 48.7$ & 0.009 & XII \\
\hline S. argenteolus & S. griseus subsp. solvifaciens & $43.1 / 47.1$ & 0.009 & XII \\
\hline S. badius & S. sindenensis & $38.6 / 41.5 / 37.9$ & 0.012 & $\mathrm{Vb}$ \\
\hline
\end{tabular}




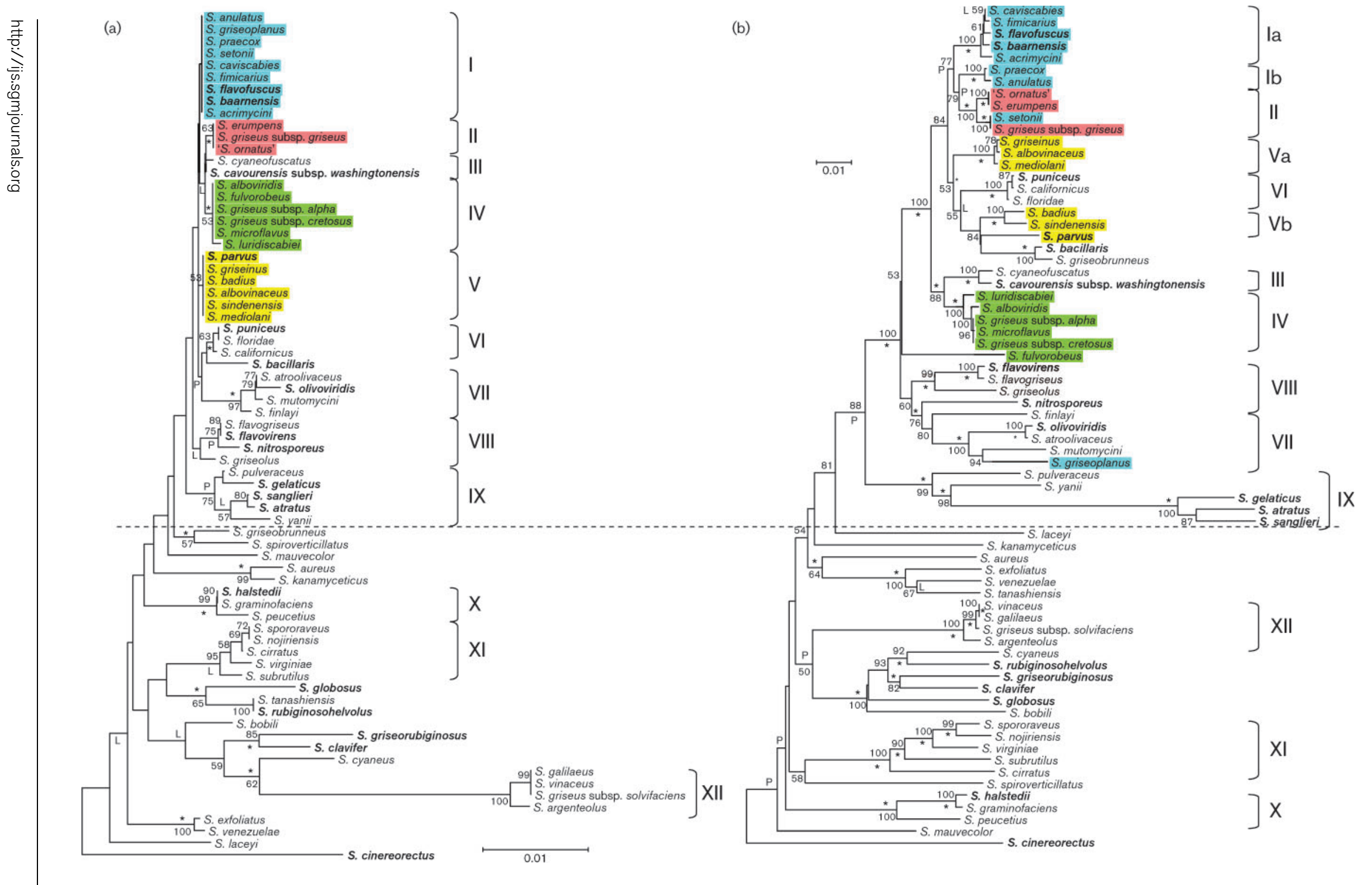

Fig. 1. Phylogenetic NJ trees based on $16 \mathrm{~S}$ rRNA gene sequences (a) and five concatenated sequences (atp $D, \operatorname{gyr} B, \operatorname{rec} A, r p o B$ and $\operatorname{trp} B$ ) (b), showing relationships of all 71 tested strains of the $S$. griseus clade and related species. Strain names and GenBank accession numbers are provided in Table 1 . The 18 additional strains included in this study are highlighted in bold. $\mathrm{P}$ and $\mathrm{L}$ indicate branches of the tree that were also determined using MP in MEGA and ML in both PAUP and PHYLIP, respectively; asterisks indicate branches that were supported by all three tree-making algorithms. Bars, $1 \%$ difference in nucleotide sequence. 
from 0.001 to 0.010 within individual clusters. It was also shown that the bootstrap support for the 16S rRNA gene tree was generally low, especially for the deeper nodes.

PCR amplification and sequencing of the atpD, gyrB, recA, $r p o B$ and $\operatorname{trp} B$ genes were successful for the 18 additional strains. GenBank accession numbers of the sequences obtained in this study are listed in Table 1. The features of each gene locus are displayed in Supplementary Table S1, available in IJSEM Online. The five genes used here are widely distributed, unique within the streptomycete genome and of adequate length to be phylogenetically informative, also showing a relatively high degree of conservation (Zeigler, 2003). In comparison with the fulllength 16S rRNA gene sequence, each individual proteincoding locus contained more variation, to different degrees. The proportion of variable sites in the alleles varied from $24.0 \%$ (atpD) to $48.1 \%$ (gyrB). $g y r B$ and $\operatorname{trp} B$ possessed higher percentages of variable sites than the other three loci, which could also be seen from the overall mean distance. Phylogenetic trees predicted from each of the five genes showed general congruence, albeit with slight differences (not shown), thus forming the basis for concatenation of multiple sequences for integrated analyses.

\section{MLSA}

The concatenated sequences of five protein-coding loci contained $2527 \mathrm{nt}$, with a mean $\mathrm{G}+\mathrm{C}$ content of $68.1 \mathrm{~mol} \%$. The sequence identities among the 71 tested strains ranged from 82.1 to $100 \%$, with an overall mean distance of 0.093 . The phylogenetic tree based on the five concatenated genes had a similar topology to the $16 \mathrm{~S}$ rRNA gene tree, and most of the 16S rRNA gene clusters were maintained, with clearly better discriminated entities and higher bootstrap support (Fig. 1b). The results of a larger MLSA study with 18 additional strains demonstrated again that the MLSA phylogeny was generally congruent with the traditional 16S rRNA gene phylogeny, and showed much higher power of discrimination and much more stable topological structure than the latter (Guo et al., 2008).

A couple of clusters were split in the five-gene tree. The nine strains of cluster I were divided mainly into two stable clusters, containing Streptomyces acrimycini, S. baarnensis, S. caviscabies, S. fimicarius and S. flavofuscus in cluster Ia, with sequence distances of 0.001-0.006, and Streptomyces anulatus and $S$. praecox in cluster $\mathrm{Ib}$, with a distance of 0.002 . The same situation was found with the six strains of cluster V, which were mainly divided into cluster Va, harbouring Streptomyces albovinaceus, S. griseinus and S. mediolani with sequence distances of 0.001-0.002, and cluster $\mathrm{Vb}$, harbouring Streptomyces badius and S. sindenensis with a distance of 0.012 in the five-gene tree. Moreover, Streptomyces fulvorobeus of cluster IV was located at the periphery of a well-circumscribed subclade consisting of clusters I-VI, and Streptomyces griseoplanus consistently shifted from cluster I to cluster VII.
The development of sequencing techniques and the convenience of the internet allow us to obtain and share large amounts of sequence information to define species by MLSA. There is evidence that a representative small set of shared genes can successfully predict genome relatedness (Zeigler, 2003). Comparing phylogenetic trees reconstructed from concatenations of all six genes (not shown), the five protein-coding genes (Fig. 1b) and combinations of four or three protein-coding genes (Supplementary Fig. S1) inferred in this study, we found that the five-gene tree had discriminatory power and topological stability as great as or better than the six-gene tree. This is not a surprise, as the DNA G + C contents of the five genes were closer to the content range of Streptomyces genomes, and the high evolutionary conservation of the 16S rRNA gene meant that it contributed little to the quality of the six-gene phylogeny. We also found that the concatenation of three or four genes had good resolution and robustness, although a few branches were poorly resolved or showed dissimilar structures. Even a concatenation of the three most conserved genes, atpD-recA-rpoB, gave good discriminatory power and stability for differentiating most of the strains (Supplementary Fig. S1a). When genes with more variable sites (e.g. $\operatorname{gyr} B$ and $\operatorname{trp} B$ ) were used, the discriminatory power increased, and the concatenations atpD-rpoB-gyrB and $g y r B-r e c A-r p o B$ seemed superior to other three-gene datasets considering both resolution and general topology. The four-gene tree was superior to the three-gene tree in stability and discriminatory power and was more similar to the five-gene tree (Supplementary Fig. S1b). It is therefore concluded that MLSA based on concatenation of five protein-coding genes is better than the previous six-gene scheme (Guo et al., 2008) in that it provides equally good resolution and stability to resolve unitary relationships among streptomycetes, and is more cost-effective to apply in practice; meanwhile, the three- or four-gene schemes can also be applicable to everyday use where identification and discrimination are required in the discovery of novel isolates. Moreover, the MLSA scheme is found to be more suitable for discriminating strains with $>99 \% 16$ S rRNA gene sequence similarity, e.g. strains in the upper section indicated by the dashed line in Fig. 1.

\section{DDH values and comparison with MLSA evolutionary distances}

DDH values have been used since the 1960s to determine relatedness between strains and are viewed as the most important criterion in the delineation of bacterial species, as it was one of the few universally applicable techniques available that could offer truly genome-wide comparisons between organisms (Stackebrandt \& Goebel, 1994; Stackebrandt et al., 2002). In this study, representative strains with different MLSA evolutionary distances ranging from 0.001 to 0.012 in the five-gene tree were selected for further DDH analysis. The DDH values among these strains are shown in Table 2. The three species of cluster VI, namely Streptomyces californicus, S. floridae and S. puniceus, 
which were cohesively related with MLSA distances of $0.001-0.002$, shared DDH values of $84.1-89.6 \%$; Streptomyces flavogriseus and S. flavovirens, with an MLSA distance of 0.004 , had a DDH value around $87.5 \%$; all other representative strains with MLSA distances of 0.0050.007 had DDH values between 75.9 and $86.5 \%$, whereas the DDH values between strains with MLSA distances of $0.009-0.012$ were lower than $50 \%$.

The relationship between DDH and MLSA distance was described by a linear regression model. It was clear from Fig. 2 that the DDH value correlated strongly $\left(r^{2}=0.77\right)$ with the MLSA evolutionary distance, and the $70 \% \mathrm{DDH}$ value for the current species definition corresponded to an MLSA distance of 0.007 . The representative strains with MLSA sequence distances $\leqslant 0.007$ consistently showed high DDH values, well above the $70 \%$ threshold generally recognized for species definition (Wayne et al., 1987). As for the individual genes, the DDH value had relatively poor correlation with evolutionary distance for atpD $\left(r^{2}=0.60\right)$, $\operatorname{gyr} B\left(r^{2}=0.56\right)$ and $\operatorname{rec} A\left(r^{2}=0.67\right)$ and very poor correlation with distance for $r p o B\left(r^{2}=0.04\right)$ and $\operatorname{trpB}\left(r^{2}=0.001\right)$ (Supplementary Fig. S2), mainly ascribable to their uncertain power for species delineation. Consequently, the five-gene MLSA distance of 0.007 could be considered as the species cut-off for the $S$. griseus clade, suggesting that species with five-gene sequence distances $\leqslant 0.007$ in this clade should be assigned to the same genomic species.

The DDH value of around $80 \%$ between S. griseus subsp. griseus and 'S. ornatus', which represented the two branches of cluster II with an MLSA distance of 0.007, confirmed again that the four species of cluster II belonged to the same species, which was also supported by DDH data from previous studies (Okanishi, 1972; Liu et al., 2005). S. griseus subsp. solvifaciens and the two closely related (0.002 MLSA distance) strains assigned to Streptomyces galilaeus and $S$. vinaceus within cluster XII have been transferred to Streptomyces albidoflavus in our earlier study (Rong et al., 2009). In cluster Ia, S. acrimycini had the largest sequence distances from S. baarnensis (0.005) and S. flavofuscus (0.006), and shared respective mean DDH values of 84.3 and

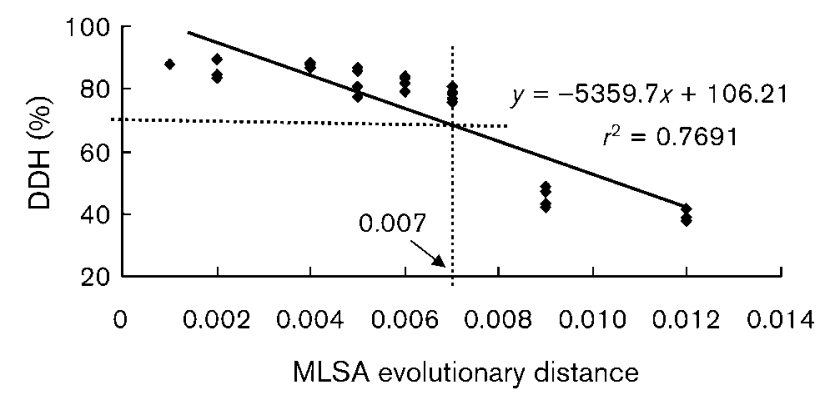

Fig. 2. Relationship between five-gene MLSA evolutionary distance and DDH value. Each solid diamond represents the MLSA evolutionary distance ( $x$-axis) between two strains plotted against the $\mathrm{DDH}$ value ( $y$-axis) of the strains.
$83.2 \%$ with the latter, indicating that all five species within this cluster should be combined into one species. Similarly, S. anulatus and S. praecox of cluster Ib, the species of cluster $\mathrm{Va}$, the species of cluster VI, all species except $S$. fulvorobeus within cluster IV, S. atroolivaceus and S. olivoviridis within cluster VII, S. flavogriseus and S. flavovirens within cluster VIII and S. graminofaciens and S. halstedii within cluster X should also be combined into single species.

Streptomyces cavourensis subsp. washingtonensis was described as a heterotypic synonym of $S$. griseus by $\mathrm{Wu}$ et al. (2008). However, based on our MLSA data, S. cavourensis subsp. washingtonensis was located in cluster III and was apparently far from S. griseus subsp. griseus (MLSA distance of 0.033), in cluster II; moreover, $S$. cavourensis subsp. washingtonensis shared an MLSA distance of 0.007 and a DDH value of more than $70 \%$ with S. cyaneofuscatus, located in the same cluster. It is therefore proposed that $S$. cavourensis subsp. washingtonensis should be recognized as a later heterotypic synonym of S. cyaneofuscatus rather than S. griseus.

Besides the genotypic evidence, all the strains reported here to belong to species whose names are synonyms were consistent in cultural and morphological characteristics, as exemplified by S. californicus, S. floridae and S. puniceus in cluster VI, which produced unusual aubergine-coloured substrate mycelium and light red-purple aerial spore mass on ISP 2 agar and formed extensively branched substrate hyphae and aerial hyphae that carried smooth-surfaced spores in rectiflexibiles spore chains.

Our results demonstrated that MLSA based on five protein-coding housekeeping genes could provide refined species and even intraspecies evaluation for streptomycetes, and the data correlated significantly with DDH data. The MLSA procedure thus can be used as a practical, reliable and robust alternative to DDH for the identification and classification of streptomycetes. Recently, it has been strongly proposed that ecological aspects of bacteria should be considered and included in the definition of prokaryote species (Achtman \& Wagner, 2008; Cohan \& Koeppel, 2008; Koeppel et al., 2008). Antony-Babu et al. (2008) found that S. griseus strains that showed $>99 \% 16 \mathrm{~S}$ rRNA gene sequence similarity could be separated into distinct ecovars based on MLSA in combination with carbon utilization properties, thereby providing evidence of niche variation in this taxon. In light of these findings, our MLSA scheme is of great biological significance by providing an elaborate taxonomic grouping of streptomycete diversity, and will benefit both ecology and bioprospecting of these ubiquitous micro-organisms.

\section{Taxonomic proposals}

On the basis of MLSA and DDH data, combined with cultural and morphological properties, the 29 species and three subspecies of Streptomyces griseus clade in fact represent the following 11 species. According to Rule 38 
of the Bacteriological Code (Lapage et al., 1992), the oldest legitimate species name has priority over the names of other species, and should be retained for the merged species.

Streptomyces albovinaceus (Kudrina 1957) Pridham et al. $1958^{\mathrm{AL}}$ has the following later heterotypic synonyms: Streptomyces griseinus Waksman $1959^{\mathrm{AL}}$ and Streptomyces mediolani Arcamone et al. $1969^{\mathrm{AL}}$.

Streptomyces anulatus (Beijerinck 1912) Waksman $1953^{\mathrm{AL}}$ has the following later heterotypic synonym: Streptomyces praecox (Millard and Burr 1926) Waksman $1953^{\mathrm{AL}}$.

Streptomyces atroolivaceus (Preobrazhenskaya et al. 1957) Pridham et al. $1958^{\mathrm{AL}}$ has the following later heterotypic synonym: Streptomyces olivoviridis (Kuchaeva et al. 1960) Pridham $1970^{\mathrm{AL}}$.

Streptomyces bacillaris (Krasil'nikov 1958) Pridham 1970 ${ }^{\mathrm{AL}}$ has the following later heterotypic synonym: Streptomyces griseobrunneus Waksman $1961^{\mathrm{AL}}$.

Streptomyces cyaneofuscatus (Kudrina 1957) Pridham et al. $1958^{\mathrm{AL}}$ has the following later heterotypic synonym: Streptomyces cavourensis subsp. washingtonensis Skarbek and Brady $1978^{\mathrm{AL}}$.

Streptomyces fimicarius (Duché 1934) Waksman and Henrici $1948^{\mathrm{AL}}$ has the following later heterotypic synonyms: Streptomyces acrimycini (Preobrazhenskaya et al. 1957) Pridham et al. $1958^{\mathrm{AL}}$, Streptomyces baarnensis Pridham et al. $1958^{\mathrm{AL}}$, Streptomyces caviscabies Goyer et al. $1996^{\mathrm{VP}}$ and Streptomyces flavofuscus (Kudrina 1957) Preobrazhenskaya $1986^{\mathrm{VP}}$.

Streptomyces flavovirens (Waksman 1923) Waksman and Henrici $1948^{\mathrm{AL}}$ has the following later heterotypic synonym: Streptomyces flavogriseus (Duché 1934) Waksman and Lechevalier $1953^{\mathrm{AL}}$.

Streptomyces griseus (Krainsky 1914) Waksman and Henrici $1948^{\mathrm{AL}}$ has the following later heterotypic synonyms: Streptomyces erumpens Calot and Cercós $1963^{\mathrm{AL}}$, 'Streptomyces ornatus' Calot and Cercós 1963 and Streptomyces setonii (Millard and Burr 1926) Waksman $1953^{\mathrm{AL}}$.

Streptomyces halstedii (Waksman and Curtis 1916) Waksman and Henrici $1948^{\mathrm{AL}}$ has the following later heterotypic synonym: Streptomyces graminofaciens Charney et al. $1953^{\mathrm{AL}}$.

Streptomyces microflavus (Krainsky 1914) Waksman and Henrici $1948^{\mathrm{AL}}$ has the following later heterotypic synonyms: Streptomyces alboviridis (Duché 1934) Pridham et al. $1958^{\mathrm{AL}}$, Streptomyces griseus subsp. alpha (Ciferri 1927) Pridham $1970^{\mathrm{AL}}$, Streptomyces griseus subsp. cretosus Pridham $1970^{\mathrm{AL}}$ and Streptomyces luridiscabiei Park et al. $2003^{\mathrm{VP}}$.

Streptomyces puniceus Patelski $1951^{\mathrm{AL}}$ has the following later heterotypic synonyms: Streptomyces californicus
(Waksman and Curtis 1916) Waksman and Henrici $1948^{\mathrm{AL}}$ and Streptomyces floridae Bartz et al. $1951^{\mathrm{AL}}$.

\section{ACKNOWLEDGEMENTS}

We thank the culture collection CGMCC for providing strains. This work was funded by the Natural Science Foundation of China (NSFC, no. 30670002) and by the Knowledge Innovation Project of Chinese Academy of Sciences (no. KSCX2-YW-Z-042).

\section{REFERENCES}

Achtman, M. \& Wagner, M. (2008). Microbial diversity and the genetic nature of microbial species. Nat Rev Microbiol 6, 431-440.

Acinas, S. G., Marcelino, L. A., Klepac-Ceraj, V. \& Polz, M. F. (2004). Divergence and redundancy of $16 \mathrm{~S}$ rRNA sequences in genomes with multiple rrn operons. J Bacteriol 186, 2629-2635.

Akaike, H. (1974). A new look at the statistical model identification. IEEE Trans Automat Contr 19, 716-723.

Antony-Babu, S., Stach, J. E. \& Goodfellow, M. (2008). Genetic and phenotypic evidence for Streptomyces griseus ecovars isolated from a beach and dune sand system. Antonie van Leeuwenhoek 94, 63-74.

Chun, J. \& Goodfellow, M. (1995). A phylogenetic analysis of the genus Nocardia with 16S rRNA gene sequences. Int J Syst Bacteriol 45, 240-245.

Coenye, T., Gevers, D., Van de Peer, Y., Vandamme, P. \& Swings, J. (2005). Towards a prokaryotic genomic taxonomy. FEMS Microbiol Rev 29, 147-167.

Cohan, F. M. \& Koeppel, A. F. (2008). The origins of ecological diversity in prokaryotes. Curr Biol 18, 1024-1034.

Ezaki, T., Hashimoto, Y. \& Yabuuchi, E. (1989). Fluorometric deoxyribonucleic acid-deoxyribonucleic acid hybridization in microdilution wells as an alternative to membrane filter hybridization in which radioisotopes are used to determine genetic relatedness among bacterial strains. Int J Syst Bacteriol 39, 224-229.

Felsenstein, J. (1985). Confidence limits on phylogenies: an approach using the bootstrap. Evolution 39, 783-791.

Felsenstein, J. (2008). PHYLIP (phylogeny inference package) version 3.68. Distributed by the author. Department of Genome Sciences, University of Washington, Seattle, USA.

Gevers, D., Cohan, F. M., Lawrence, J. G., Spratt, B. G., Coenye, T., Feil, E. J., Stackebrandt, E., Van de Peer, Y., Vandamme, P. \& other authors (2005). Opinion: re-evaluating prokaryotic species. Nat Rev Microbiol 3, 733-739.

Gevers, D., Dawyndt, P., Vandamme, P., Willems, A., Vancanneyt, M., Swings, J. \& De Vos, P. (2006). Stepping stones towards a new prokaryotic taxonomy. Philos Trans R Soc Lond B Biol Sci 361, 19111916.

Guo, Y., Zheng, W., Rong, X. \& Huang, Y. (2008). A multilocus phylogeny of the Streptomyces griseus 16S rRNA gene clade: use of multilocus sequence analysis for streptomycete systematics. Int J Syst Evol Microbiol 58, 149-159.

He, L., Li, W., Huang, Y., Wang, L., Liu, Z., Lanoot, B., Vancanneyt, M. \& Swings, J. (2005). Streptomyces jietaisiensis sp. nov., isolated from soil in northern China. Int J Syst Evol Microbiol 55, 1939-1944.

Kämpfer, P. (2006). The family Streptomycetaceae. Part I. Taxonomy. In The Prokaryotes, 3rd edn, vol. 3, pp. 538-604. Edited by M. Dworkin, S. Falkow, E. Rosenberg, K. H. Schleifer \& E. Stackebrandt. New York: Springer. 
Kimura, M. (1980). A simple method for estimating evolutionary rates of base substitutions through comparative studies of nucleotide sequences. J Mol Evol 16, 111-120.

Koeppel, A., Perry, E. B., Sikorski, J., Krizanc, D., Warner, A., Ward, D. M., Rooney, A. P., Brambilla, E., Connor, N. \& other authors (2008). Identifying the fundamental units of bacterial diversity: a paradigm shift to incorporate ecology into bacterial systematics. Proc Natl Acad Sci U S A 105, 2504-2509.

Lanoot, B., Vancanneyt, M., Hoste, B., Vandemeulebroecke, K., Cnockaert, M. C., Dawyndt, P., Liu, Z., Huang, Y. \& Swings, J. (2005a). Grouping of streptomycetes using 16S-ITS RFLP fingerprinting. Res Microbiol 156, 755-762.

Lanoot, B., Vancanneyt, M., Van Schoor, A., Liu, Z. \& Swings, J. (2005b). Reclassification of Streptomyces nigrifaciens as a later synonym of Streptomyces flavovirens; Streptomyces citreofluorescens, Streptomyces chrysomallus subsp. chrysomallus and Streptomyces fluorescens as later synonyms of Streptomyces anulatus; Streptomyces chibaensis as a later synonym of Streptomyces corchorusii; Streptomyces flaviscleroticus as a later synonym of Streptomyces minutiscleroticus; and Streptomyces lipmanii, Streptomyces griseus subsp. alpha, Streptomyces griseus subsp. cretosus and Streptomyces willmorei as later synonyms of Streptomyces microflavus. Int J Syst Evol Microbiol 55, 729-731.

Lapage, S. P., Sneath, P. H. A., Lessel, E. F., Skerman, V. B. D., Seeliger, H. P. R. \& Clark, W. A. (1992). International Code of Nomenclature of Bacteria: Bacteriological Code, 1990 Revision. Washington, DC: American Society for Microbiology.

Liu, Z., Shi, Y., Zhang, Y., Zhou, Z., Lu, Z., Li, W., Huang, Y., Rodriguez, C. \& Goodfellow, M. (2005). Classification of Streptomyces griseus (Krainsky 1914) Waksman and Henrici 1948 and related species and the transfer of 'Microstreptospora cinerea' to the genus Streptomyces as Streptomyces yanii sp. nov. Int J Syst Evol Microbiol 55, 1605-1610.

Martens, M., Delaere, M., Coopman, R., De Vos, P., Gillis, M. \& Willems, A. (2007). Multilocus sequence analysis of Ensifer and related taxa. Int J Syst Evol Microbiol 57, 489-503.

Martens, M., Dawyndt, P., Coopman, R., Gillis, M., De Vos, P. \& Willems, A. (2008). Advantages of multilocus sequence analysis for taxonomic studies: a case study using 10 housekeeping genes in the genus Ensifer (including former Sinorhizobium). Int J Syst Evol Microbiol 58, 200-214.

Mignard, S. \& Flandrois, J. P. (2008). A seven-gene, multilocus, genus-wide approach to the phylogeny of mycobacteria using supertrees. Int J Syst Evol Microbiol 58, 1432-1441.

Naser, S. M., Vancanneyt, M., Hoste, B., Snauwaert, C., Vandemeulebroecke, K. \& Swings, J. (2006). Reclassification of Enterococcus flavescens Pompei et al. 1992 as a later synonym of Enterococcus casseliflavus (ex Vaughan et al. 1979) Collins et al. 1984 and Enterococcus saccharominimus Vancanneyt et al. 2004 as a later synonym of Enterococcus italicus Fortina et al. 2004. Int J Syst Evol Microbiol 56, 413-416.
Okanishi, M. (1972). An evaluation of taxonomic criteria in streptomycetes on the basis of deoxyribonucleic acid homology. J Gen Microbiol 72, 49-58.

Posada, D. \& Crandall, K. A. (1998). Modeltest: testing the model of DNA substitution. Bioinformatics 14, 817-818.

Rong, X., Guo, Y. \& Huang, Y. (2009). Proposal to reclassify the Streptomyces albidoflavus clade on the basis of multilocus sequence analysis and DNA-DNA hybridization, and taxonomic elucidation of Streptomyces griseus subsp. solvifaciens. Syst Appl Microbiol 32, 314322.

Rosselló-Mora, R. (2006). DNA-DNA reassociation methods applied to microbial taxonomy and their critical evaluation. In Molecular Identification, Systematics and Population Structure of Prokaryotes, pp. 23-50. Edited by E. Stackebrandt. Heidelberg: Springer.

Shirling, E. B. \& Gottlieb, D. (1966). Methods for characterization of Streptomyces species. Int J Syst Bacteriol 16, 313-340.

Stackebrandt, E. \& Goebel, B. M. (1994). Taxonomic note: a place for DNA-DNA reassociation and 16S rRNA sequence analysis in the present species definition in bacteriology. Int J Syst Bacteriol 44, 846849.

Stackebrandt, E., Frederiksen, W., Garrity, G. M., Grimont, P. A. D., Kämpfer, P., Maiden, M. C. J., Nesme, X., Rosselló-Mora, R., Swings, J. \& other authors (2002). Report of the ad hoc committee for the reevaluation of the species definition in bacteriology. Int J Syst Evol Microbiol 52, 1043-1047.

Swofford, D. L. (2002). PAUP*: Phylogenetic analysis using parsimony (and other methods), version 4. Sunderland, MA: Sinauer Associates.

Tamura, K., Dudley, J., Nei, M. \& Kumar, S. (2007). MEGA4: molecular evolutionary genetics analysis (MEGA) software version 4.0. Mol Biol Evol 24, 1596-1599.

Vandamme, P., Pot, B., Gillis, M., De Vos, P., Kersters, K. \& Swings, J. (1996). Polyphasic taxonomy, a consensus approach to bacterial systematics. Microbiol Rev 60, 407-438.

Wayne, L. G., Brenner, D. J., Colwell, R. R., Grimont, P. A. D., Kandler, O., Krichevsky, M. I., Moore, L. H., Moore, W. E. C., Murray, R. G. E. \& other authors (1987). International Committee on Systematic Bacteriology. Report of the ad hoc committee on reconciliation of approaches to bacterial systematics. Int J Syst Bacteriol 37, 463-464.

Wu, X., Wen, Y., Qian, C., Li, O., Fang, H. \& Chen, W. (2008). Taxonomic study of a chromomycin-producing strain and reclassification of Streptomyces cavourensis subsp. washingtonensis as a later synonym of Streptomyces griseus. Int J Syst Evol Microbiol 58, 27832787.

Young, J. M., Park, D. C., Shearman, H. M. \& Fargier, E. (2008). A multilocus sequence analysis of the genus Xanthomonas. Syst Appl Microbiol 31, 366-377.

Zeigler, D. R. (2003). Gene sequences useful for predicting relatedness of whole genomes in bacteria. Int J Syst Evol Microbiol 53, 18931900. 